\title{
Разновидности текстовой динамики в свете феномена признаковости в повести Ф. М. Достоевского «Двойник» (Статья первая)*
}

\author{
КАТАЛИН КРОО** \\ ELTE BTK Orosz Nyelvi és Irodalmi Tanszék, H-1088 Budapest, Múzeum krt. 4/D. \\ Томский политехнический университет, пр. Ленина, 30, RU-634050 Томск \\ Received: 12 June 2020 • Accepted: 30 August 2020 \\ Published online: 13 September 2021 \\ (C) 2021 The Author
}

\begin{abstract}
АННОТАЦИЯ
В настоящей статье изучаются поэтические принципы и функции двух типов структурно-семантической логики, влияющей на возникновение текстовой динамики в «Двойнике». Парадоксально, что главная линия развития сводится к структуре высокой повторяемости рекуррентных / рекурсивных фигурирований стабильных нарративных единиц, мотивов, лексических элементов текста. Их постоянное возвращение (см. события, характерные черты персонажа, семантические признаки, компоненты устойчивых фразеологических выражений) создает впечатление модели неизменного мира, в котором не происходит никаких смен. Такой феномен можно условно назвать динамикой рекуррентности под знаком статичности. Транспозиционная динамика, с другой стороны, определяется в качестве второго направления текстового развертывания, формирующего механизм порождения смысла. Транспозиция в данной работе понимается в широком смысле, со специальным сосредоточением на 1) трансфигурации и проекции смысла путем сдвига от однородности семантических признаков к наделению означающих или означаемых новыми признаками (проблема референтности); 2) процессах семантической интеграции, касающейся включения мелких смысловых единиц в более крупные формации (семантический признак $\rightarrow$ мотив $\rightarrow$ литературный персонаж).
\end{abstract}

\footnotetext{
* Продолжение настоящей работы (Статика и динамика в повести Ф. М. Достоевского «Двойник» в контексте проблемы признаковости [Часть вторая]) включено в книгу Универсалии русской литературы 8. Сборник статей. Под ред. А. А. Фаустова и М. Фрайзе. Воронеж: Издательский дом ВГУ, 2020. 192-220. Обе статьи выполнены при финансовой поддержке РФФИ (№ 19-512-23008) и в рамках программы повышения конкурентоспособности ТПУ.

${ }^{* *}$ Corresponding author. E-mail: katalinkroo@gmail.com
} 
Цель статьи состоит в выяснении взаимоотношения (своеобразной интеракции) двух типов динамики. Рассматриваемое смысловое образование, воплощаемое в минимальной единице моторной (моторно-словесной) «экспрессии» Голядкина, обладает двойной ориентацией, основанной на корреляции движения и остановки, которую В. В. Виноградов интерпретировал в своей знаменитой работе. С точки зрения объекта изучения в настоящей статье указанная нарративная и лингвистическая единица подвергается толкованию в качестве рекурсивной пары мотивов, обладающей особенной способностью перевоплощаться путем транспозиции. Применением метода «сlose reading» в пятой главе повести, где появляется двойник господина Голядкина, подробно продемонстрировано, как транспозиция действует в рамках процесса смысловых интеграций. Значение мотива врага претерпевает сдвиг от смысла человеческого врага к смыслу петербургской погоды и человеческой судъбы как новых субъектов. Они ассоциируются с мифологией и литературной культурой (интертексты), подводящими к толкованию личности Голядкина. Образ главного героя проецируется на его двойника многими семантическими признаками. «Тоскливая побежка» в смысле столкновения Голядкина с самим собой представляет его в качестве прозревающего героя, который как литературный персонаж развивается постепенно, включением в этот процесс и образ двойника как транспозицию фигуры, также представляющей собой динамическое смысловое образование. Соотношение Голядкина и его двойника в аспекте проблемы первичности и вторичности поставлено также в контекст семиотики Пирса.

\section{КАЮЧЕВЫЕ САОВА}

Достоевский, Двойник, рекуррентность / рекурсивность, транспозиционная динамика, трансформация, интеграция, семантические признаки, моторно-словесное выражение, семиотика

\section{1. ПРОБЛЕМА «НЕИЗМЕННОСТИ» И ПЕРЕВОПЛОЩЕНИЯ В СЮЖЕТЕ, ХАРАКТЕРЕ И ЯЗЫКЕ}

\section{1. Устойчивость в повторах в перспективе статики}

Исходим из простого читательского впечатления: в повести Достоевского «Двойник» наблюдается мало моментов радикальных продвижений вперед как в сюжетосложении, так и в более узких рамках оформления образа Голядкина-старшего. Читателем, следящим за сюжетным маршрутом главного героя, все сильнее овладевает чувство, что хотя Голядкину предоставлена возможность и перспектива совершенно измениться в ходе психологических и умственных своих «приключений», он не способен последовательно, полно проходить путь существенного перевоплощения личности и аутентичной самоидентификации, в его самопонимании недостает осознания и осмысления каких бы то ни было черт метаморфоз. Главный аспект определения характера по ходу текстового развертывания сводится к языковому воплощению речи Голядкина в ее повествовательном воспроизведении, с доминантой устойчивых слов, словесных оборотов - как указывает В. В. Виногра- 
дов: «застывших формул» (Виноградов 1976: 110). ${ }^{1}$ Они до конца произведения остаются в действии, хотя повествователь задает ироническую модальность, комически-издевательский тон по отношению к противоречиям своего героя, которые получают наглядное отражение и в его собственной повествовательной речи. ${ }^{2}$ Противоречия Голядкина как в плане характера, так и мотивации поступков сохраняются до конца.

Сюжет, образ литературного персонажа в целом и язык - три весомых компонента возникновения эффекта неизменности: «- Нет-с, я ничего, Яков Петрович, - покорным голосом пробормотал наш герой» $\left(221^{3}\right)$ - сообщает повествователь в последней главе произведения, где Голядкин пользуется тем же выражением «я ничего», как и в начале. В заключительном эпизоде своих общественных и психологических авантюр он все еще просит «другого Якова Петровича содействовать ему при всех будущих начинаниях и не оставлять его в критическом случае» (226); и таким же образом желает «пролезть... в какую-нибудь мышиную щелочку» (224), когда - вопреки всем его стараниям - его обнаруживают, как в начале повести, где описывается, как он прячется в карете от глаз начальника отделения во время своего необыкновенного выезда на Невский проспект (127). Соответственно, он с первого момента до конца одержим желанием «провалиться сквозь землю» (127), «спрятаться» (139), «улизнуть» (166), «стушеваться» (135) в неловких ситуациях. В изображении последних пережитых Голядкиным событий не один раз повторяются ссылки на то, что герой в каком-то смысле предчувствовал, ожидал, даже «знал заранее» (224) то, что произойдет с ним (повесть и заканчивается на идее, заложенной в последнем предложении: «Герой наш вскрикнул и схватил себя за голову. Увы! Он это давно уже предчувствовал!», 226). Читатель, однако, уже многократно убеждался в том, что хотя какие-то элементы понимания и прозрения на определенных этапах осознания событий нередко приходят, сопровождая мысль, что «дело с концом» (220), в следующую минуту герой обычно опять хочет опереться на идею и надежду, что все может еще «перемениться», «уладиться к лучшему» (215), «улучшиться к лучшему» (220). ${ }^{4}$

1 Н. С. Трубецкой помимо «фиксированных» формул указывает и на табуированные выражения, референт которых в речи Голядкина определяется опосредованием. Оба типа слов одинаково характерны для внутренней и внешней речи героя, в то время как перебивания, постоянные самокоррекции, синтаксические остановки отсутствуют во внутренних высказываниях. По мнению исследователя, из двух стилей языка в разговорах (диалогах) с самим собой Голядкин прибегает к своей энергичной речи (TRUBETZKOY 1948: 166).

2 В. Шмид указывает, что хотя и «повествование о хитрых и лукавых поступках двойника в большинстве случаев выдержано в стиле голядкинской речи и насыщено голядкинскими оценками», даже в таком тексте, где «персонализация доведена до крайности», «персональное восприятие может не облекаться в персональные оценки и языковые особенности персонажа» (Шмид 2003: 134).

«Двойник» Достоевского здесь и далее цитируется с указанием страниц по: Достоввский 1972. Выделения курсивом наши - К. К.

4 Такая неизменность как идея, переданная крупными повторами, указывает на необходимость дать интерпретационные рамки для всех событий, в которых наблюдается динамика благодаря их повторениям в длинном ряду: повторы как бы обрамляют повторения (несущие смысл многочисленности / бесконечности), в том смысле как Н. В. Маклакова и Е. В. Шорова различают эти термины в философском контексте теорий С. Кьеркегора и Ж. Делёза (см. МАкЛАковА-ШоровА 2016). 


\section{2. «Статика» в перспективе динамики повторяемости, порождающей семантику беспризнаковости}

Под читательским восприятием основной неизменности Голядкина, впечатлением статичного мира, тем не менее, кроется определенная разновидность динамики, которую условно можно назвать динамикой рекуррентности. Она предполагает маленькие и крупные циклы отдаления, а затем возвращения к определенным поступкам, мыслям, жестам и выражениям, служащим мотивировочным объяснением движения героя в сюжете, а также в словесном его поведении, которое составляет в чистой или модально окрашенной форме часть повествовательного дискурса. Во всех указанных элементах и в их чередованиях воплощается семантика удвоенности. Если в конце повести во многих аспектах наблюдается возвращение к началу, а это осмысляется как крупный сюжетный цикл и охват словесного процесса в своей повторяемости, то между изначальной и конечной точками проявляются многочисленные сюжетные и языковые события рекуррентности, ${ }^{5}$ которые ученые определяли через разные метафоры, как, например, «зигзагообразное» движение (Виноградов 1976: 112), «топтание на одном месте» (Шкловский 1957: 61). Обе метафоры любопытны тем, что они пригодны для определения смысла двойственности (топтание на месте / ходить туда-сюда; в плане сюжета это конкретизируется как дилемма выбора одного или другого, но указывается не просто сама дилемма противопоставленных возможностей, но и удвоенный ответ в форме чередования одного и другого конкретных моментов двух возможностей), - сначала правая нога, затем левая, условно говоря, и «зиг» и «заг». Такая зигзагообразность моторных образов, соответствующих фазам душевной диспозиции для интеллектуальных решений или скорее нерешений героя в выборе четко маркированных альтернатив, созвучна разным формам утверждения текстом неопреде ленности элементов и явлений означаемого мира и неспособности героя обозначить их индивидуальными признаками.

Напомним указанный Виноградовым известный пример триединой структуры: Голядкин «...не зная, что далее делать, взял стул и сел. Но, вспомнив, что уселся без приглашения... немедленно встав... нимало не медля... наконец сел окончательно и уже не вставал более» (114-115; Виноградов 1976: 112). Такие случаи, когда Голядкин на фоне вопроса Одно или другое? немотивированно выбирает первую возможность, противопоставленную осмысляемой и как бы уже выбранной им второй, могут считаться семантизацией рекуррентности в составе микроцикличности мышления, чувства, языка. Все свои примеры разных типов повторов и несовместимостей Виноградов толкует объясняя комический эффект, определяя помимо прочего результат стилистического однообразия речи как у Голядкина, так и в более широких рамках дискурса.

Остановимся на этом качестве однообразности. Стилистическое единообразие в своем семантическом прочтении означает одинаковость, при которой один элемент тот же,

\footnotetext{
5 В такой форме умножения рекуррентности проявляется своеобразный для поэтики «Двойника» процесс повторений, толкование значения которого в контексте проблемы динамики является объектом исследования в настоящей работе. Концептуализация И. П. Смирновым «удвоенной рекуррентности» в смысле перехода внутреннего параллелизма (интрапараллелизм) во внешний (интерпараллелизм) благодаря повтору прекращенного повтора (Смирнов 2001: 235-241) для нашего токования будет иметь большое значение при более позднем уточнении связи между микро- и макроструктурными элементами повторений (ср. с выражениями ученого «макроотрезки» и «микроотрезки», Смирнов 2001: 247).
} 
что другой. Возникает формула одно то же, что другое, смысл такой единости возникает за счет отсутствия определимости дифференциального признака, т. е. индивидуальной признаковости элементов в оценке их отношения. К стилистическому однообразию ведет, по мнению Виноградова, исчерпывающая «регистрация всех возможных действий», в их беспрестанной повторяемости; а повторами глагольных образований в новой синтаксической единице (например, «...выпрыгнул из постели... Выпрыгнув из постели...», 109; Виноградов 1976: 109) выделяется постоянная смена движения. Если оценить дискурсивное явление семантически, а не стилистически, то по сути дела речь идет о такой мельчайшей сегментации (процесса переживания внешнего и внутреннего), при которой выясняется, что все единицы как изображающего, так и изображаемого языка становятся эквивалентами. В любой момент может появиться неожиданный элемент в процессе исчерпывающего деления мира, который имеет такое же право на существование, как предыдущий или последующий, так как не создается иерархия в системе деталей описания. Беспрестанный процесс сегментации ставит в семантическую эквивалентность все маленькие детали, как сегменты времени, так и компоненты обозначаемых переживаний и языка их описания (мотивы). Это и приводит к впечатлению семантической унификации сегментов мира и моделирующего языка по принципу лишения их индивидуальной признаковости. Голядкин может и сесть и встать и опять сесть, без определения достоверной причинно-следственной мотивации; его образу возможно в каждый момент (моментально) приписывать новые атрибуты действия и его непонятного поворота, смены моторного движения и внутреннего переживания не только в плане противопоставленностей, но и в наборе любых признаков в рамках исчерпывающего деления отображающих и отображаемых процессов. Все это функционально приводит к тому, что в тексте господствует идея индивидуальной беспризнаковости. Языковая стратегия, кроющаяся в постоянном удваивании в рамках выбора одного или другого, а также релятивизация атрибутов благодаря их мультиплицированному обилию, как и разные неопределенности (изображающего и изображаемого) служат формами семантизации беспризнаковости.

Такая имплицитная семантизация беспризнаковости, которая, созвучно с фигурой «двойника» (хотя и вне форм явной тематизации), поднимает проблему одинаковости и расхождения, в компоновке разных видов рекуррентности последовательно и сильно действует в трех направлениях: 1) в рамках сюжета выдвигает на передний план случайность, в смысле непредсказуемости, растягивая пределы потенциала для любого элемента превращаться в ранг сюжетной реалии или семантического атрибута; 2) в плане конструкции литературного персонажа акцентируется недостаток индивидуальной личности; ставится вопрос потери или приобретения личностного характера; 3) в области языковой семантизации и целостного построения текста вырисовывается доминанта смысловых аналогий как эквивалентизирующих процессов. Речь идет не только о маленьких единицах (сидеть или встать, дернуть звонок или нет) и не лишь об оппозициях, но и о том, что поэтическая система с установкой на семантизацию беспризнаковости допускает эквивалентность любых компонентов как изображаемого, так и изображающего мира, включая в системность также соотношение этих двух пластов семиозиса (в смысле текста-метатекста). Возвращаясь к исходному пункту изложения, можно подчеркнуть, что возникновение впечатления статичности, за которой была обнаружена динамика рекуррентности, вводит в одно смысловое пространство параллелей не только сюжет и конструкцию литературного персонажа (включая его речь), но и целостный художественный дискурс произведения, 
в котором, например, микроцикличность и макроцикличность языковой рекурсивности оказываются гармонично созвучными семантике изображаемого.

Суммируя замысел, заложенный в указанных поэтических стратегиях в тексте «Двойника», можно прийти к заключению, что в русле динамики рекуррентности за счет впечатления неизменности создается установка на семантизацию беспризнаковости, которая акцентирует эквивалентность внутри (например, сюжет) и между разными сферами обозначения (уровни текста / области моделирования; например, конструкт персонажа, текст-метатекст). Виноградов, толкуя всю эту проблему с точки зрения стилистики, в определенном смысле тоже обращает внимание на семиотическую сторону вопроса, когда утверждает, что комическое впечатление заключается в нарушении соответствия между фразой / формулой (т. е. означающим) и содержанием (т. е. означаемым). В рамках беспризнаковости указанное соответствие подобным образом нарушается и в структуре бинарности, и в структуре такого мультиплицирования, которое реализуется путем исчерпывающего деления как означающих, так и означаемых элементов. Аналогичный принцип действует и в плане текстовой динамики, вопроса, из которого мы исходили. Впечатление статичности оказывается функциональным эквивалентом динамики рекуррентности, которая работает в реляции между двумя точками (А - Б; смысл - противоположный смысл; начало - конец действия или текста), но проявляется и в том процессе, по ходу которого читатель обнаруживает умножение данной реляции в форме многократного его повторения между двумя пунктами (между началом и концом микро- и / или макроструктур).

\section{3. Динамика ресемантизации повторов в процессе смысловых трансформаций и транспозиций}

В свете сказанного вернемся к метафорам Шкловского и Виноградова. Топтание ногами не сводится к разовому акту поднятия правой и левой ног (в семантическом смысле: двойного ответа на вопрос двойственности личности); топтание в сюжете - это размножение указанного образа моторных ходов и речи. «Зигзагообразность» (туда-сюда : однодругое) развивается в процесс, в историю, в сюжет двойничества со своим семиотическим мультиплицированием (в том числе и текста-метатекста). Семантика такого изоморфизма будет отражаться в умножении фигур двойника в определенные моменты сюжетосложения (вспомним Р. Лахманн о явлении «multiplication of doublings», cp.: «the split-off parts claim a single origin» - LACHMANN 1997: 307, 308, cp. 306).

Этим мы и подошли к проблеме второй разновидности динамики текста повести. Рекуррентность удваивания на разных пластах предполагает смысловое продвижение вперед (развертывание семантического сюжета). При этом не требует специального объяснения и то своеобразие текстового построения, что при динамике рекуррентности под знаком статичности (модель неизменения) действует линеарный ход, вычерчивая процесс развертывания как событийного сюжета, так и видоизменения определенных семантических единиц, что и заставляет читателя постоянно обновлять толкование кодов смыслопорождения. Об этом единогласно свидетельствуют критические интерпретации произведения Достоевского, полностью расходящиеся в основных своих ориентациях. Одна из них сводится к убеждению, что Голядкин сходит с ума (см., например, КирАй 1969, ЗАХАРов 1985, 
ROSENSHIELD 1996), ${ }^{6}$ и тогда заключение действия (появление врача) воплощает кульминацию данной линеарной сюжетной динамики. В противоположном направлении оценки пути литературного персонажа указывается, как по ходу упорного стремления героя к пониманию чего-то нового возникает сюжет прозрения (Ккоó 1998); известно и убеждение о действии в тексте самоупраздняющего («self-effacing») нарратива (GASPERETTi 1989). При всех своих различиях указанные концепции имеют общее предположение сюжета трансформации. В подходе, представляемом в настоящей статье, внимание сосредоточивается на семантической (и семиотической) транспозициях ${ }^{7}$ в процессе трансформаций.

Раздвоение динамики на рекуррентность под знаком статичности (принцип повторения, семантизирующий беспризнаковость) и на трансформационную динамику, которая ресемантизирует как будто неизменные компоненты дискурса, можно считать аналогичным семантическому механизму развертывания сюжета с двойником в действии повести. Это становится понятным, если учесть, что рекуррентность под знаком статичности выдвигает на передний план идею одинаковости, в то время как ресемантизация (обретение нового семантического признака) ставит акцент на идее дифференцирования смысла. Из этого вытекает, что рекуррентность под знаком статичности и трансформационную динамику как две разновидности динамики следует интерпретировать и на более абстрактном уровне смыслопорождения, так как формирование одинаковости и расхождения (как в русле порождения знаков, так и восприятия и толкования значения, выражаемого в знаковом воплощении) лежит в основе семиозиса. Установка художественного произведения на семантические образования, соединяющие в себе акцентирование соотношения смысловых моментов дифференциации и одинаковости, действует в том направлении, что литературный текст обладает ориентацией на сильную авторефлексивность, обозначая этим собственный принцип текстопорождения. Это может объяснить интерпретацию повести Достоевского в тех критических работах, которые разъясняют мотив двойника в области метатекстовой семантизации (например, LACHмANN 1997).

При различении рекуррентной и трансформационной динамики, однако, следует уточнить эти понятия и подойти ближе к самому явлению, подразумеваемому названными двумя принципами порождения текста. Их семантическая функция кроется в своеобразии их взаимоотношения. Речь идет не о том, что рекуррентность под знаком статичности оказывается иллюзорной, так как трансформационные ходы переписывают как бы неизменно возвращающиеся единицы повтора. Речь идет о том, что рекуррентные компоненты до конца произведения сохраняются таким образом, что главной информацией на все новых и новых этапах их микро- и макроцикличных возвращений является именно повторяемость и неизменность. Одним словом, они служат статичной рамкой для трансформационных ходов, и даже конечный пункт трансформаций не снимает их семантическую валидность в тексте - см., например, желание Голядкина в карете, в начале действия повести, «спрятаться хоть в мышиную щелочку вместе с каретой» (127) и его полностью совпадающее с этим желание «пролезть... в какую-нибудь мышиную щелочку» (224) в самом конце повести. Сохранение значений в этом и подобных случаях оказывается не ложной семантической ориентацией, а действует полноценным конструктивным фактором

6 См., например: «Голядкин в повести не сумасшедший, а сходящий с ума» (ЗАХАРов 1985: 77).

7 О транспозиции в качестве одной из основных категорий литературно-семиотической динамики см. Kroó-Torop 2018. 
рядом с трансформационной динамикой. Второй вид динамики не деконструирует первый, а включается с ним в совместную структуру по ходу развертывания семантического универсума целостного текста. ${ }^{8} \mathrm{C}$ другой стороны, различение двух разновидностей динамики стоит объяснить и в перспективе трансформационной динамики. Ее характеристика проявляется не только в том, что она включается в совместное семантическое образование с рекуррентными единицами.

Следует указать на такие трансформации, которые воплощают транспозиции. Считаем транспозицией не простое изменение значения (до варьирующейся степени), как, например, в том случае, когда определенный мотив наделяется добавочными семантическими признаками и этим изменяется значение мотива - оно обогащается новыми смыслами. В случае транспозиции структура семантического определения (т. е. ее семиотизация) подвергается трансформации. Наблюдается, например, изменение в объеме семантического контекста, куда входит данный мотив. Такой феномен мы будем исследовать ниже, указывая на проиесс интеграции. При рассматриваемых примерах интеграции значения переносятся на другие референты, чем и расширяется референтная зона смысла. Совместная включенность означаемых в более крупное семантическое единство (как мы скоро увидим на примере ресемантизациии «врагов» Голядкина в пятой главе повести) или перенос признаков с одного референта на другой (как это проявится в представляемом ниже соотношении фигур двух Голядкиных) касаются и иерархизированности семантических конструкций. Интеграция смыслов, их перенос в качестве семантических характеристик с одного референта на другой или в более крупное смысловое образование - или, как в случае мотива двойника, с одного текстового уровня на другой (текст-метатекст), - представляет собою такую трансформационную динамику, для которой характерна транспозиция. В дальнейшем мы обратим внимание на такую транспозиционную динамику в «Двойнике».

8 Здесь следует вспомнить концептуализацию Т. Цивьян рекурсивности в поэтике романа Достоевского «Подросток» (Цивьян 1976), на которую обращает особое внимание А. Фаустов в интерпретации повествовательной дисперсии в «Идиоте» (ФАустов 2019). Цивьян понимает рекурсивность в смысле музыкального принципа развития тем, которые повторяются, чередуются друг с другом, соединяются, существуют во взаимодействии, и «перед читателем стоит задача синтезировать отдельные линии в композиционное единство». С точки зрения определения двух разновидностей динамики, для нас оказывается самым важным не противопоставление принципа рекурсивности так называемому дискурсивному принципу. При дискурсивности поступательно развиваются темы «без возвращения к более ранним <их> этапам». Дискурсивность как будто бы означает не только линеарную континуальность, но в то же время и бо́льшую степень дискретизации. Для выяснения функций двух разновидностей динамики в «Двойнике» Достоевского по работе Цивьян необходимо толковать, во-первых, то, что она раскрывает в тексте «Подростка» соотношение впечатления беспорядочности и в то же время скрупулезной структурированности в композиции времени и пространства. Во-вторых, в нашем контексте следует учесть утверждение Цивьян, согласно которому смысл рекуррентных структур помимо прочего состоит в том, что «заложенная в них информация касается развития изменения на уровне более высоком, нежели чисто феноменальный» (Цивьян 1976: 245-246). В заданности нашей методологии чтения мы понимаем под этим формы семиотизации, в которых заложено порождение смысла. В поэтике «Двойника» важно рассматривать рекурсивную / рекуррентную семантизацию и с той точки зрения, как она либо частотными и последовательными повторами (исчерпывающее деление мира) обеспечивает континуитет, либо таким образом, что не «допускается» перечисление всех моментов повторяемости, а дискурс ограничивается повтором выбранных единиц из определенного семантического ряда. Цивьян противопоставляет дискурсивное (биографическое, нашими словами: время нарративных событий) рекурсивному и в том отношении, как создается хронотоп мистерийного времени (Цивьян 1976: 246). 


\section{2. ОБРАЗ ДВОЙНИКА КАК СЮЖЕТНАЯ ИНТЕГРАЦИЯ ДВУХ РАЗНОВИДНОСТЕЙ ДИНАМИКИ: РЕКУРРЕНТНОСТЬ И ТРАНСПОЗИЦИЯ}

\section{1. Отношение фигур двух Голядкиных - первичность и вторичность в свете взаимосвязи старых и новых знаков и референтов}

Сюжет двойника (процесс семантизациии фигуры Голядкина-старшего) разворачивается вокруг вопроса идентификации, сводимой к дилемме: Кто он - вообще и более точно - по отношению к Голядкину-старшему? Само собой разумеется, что два Голядкина не могут совпадать, Голядкин-старший воплощает другого персонажа в условном событийном мире, что и значит, что каждая из двух фигур должна иметь собственную характеристику, определение индивидуальных свойств, несмотря на их "разительную схожесть» (ср. 113). Онтологическую первичность имеет Голядкин-старший - он «наш герой» (113), появляющийся первым перед глазами читателя, который с ним начинает сравнивать «новоприбывшего» (ср. 146), «новопоступившего» второго персонажа (ср. 146, 148). Быть Голядкиным-старшим - это и означает быть первым, более старым явлением во времени, с которым можно сравнивать новое явление, Голядкина-младшего. В смысле пирсовской категоризации «категория первичности (Firstness) обозначает „способ бытия того, что есть, как оно есть, положительным образом и безотносительно (without reference) к чему-нибудь другому“ (СР 8.328)» (Сироткин 2017: Введение, 0.3.2.1). В пирсовкой перспективе категорий первичности и вторичности появление двойника создает семиотические условия, при которых «наш герой», господин Голядкин, теряет свою первичность в том смысле, что перестает быть в состоянии «безотносительности» («without reference»), которое можно считать бытием «самим по себе». ${ }^{9}$ В момент появления двойника безотносительность первичности ${ }^{10}$ исчезает, распознается относительность второго явления к первому. ${ }^{11}$ Ср.: «Категория вторичности (Secondness) описывает „взаимодействие между двумя вещами, происходящее вне зависимости от любого рода [...] посредника“ (Пирс 2001: 32 = СР 1.322). Вторичность „встречает нас в таких фактах, как Другое [meets us in such facts as Another], отношение, принуждение, действие, зависимость, независимость, отрицание, событие, реальность, результат“ (Пирс 2001: 61 = СР 1.358)» (Сироткин 2017; ср. Пирс 2001).

В другом семиотическом плане двойники требуют толкования выяснением соотношения знака и референта. В этом духе обостряется в повести вопрос Кем (каким из двух персонажей) обозначается другой (кто воплощзает знак и кто представляет собой референт, к которому знак относится)?, ведь возникает дилемма: «...ничего, решительно ничего не было забыто для совершенного сходства, так что если б взять да поставить их

9 Нельзя забывать, что «само по себе» является одним из устойчивых лексических единиц в «Двойнике» - речь об этом впереди.

10 «Peirce defines [the] feeling of firstness as "an instance of that kind of consciousness which involves no analysis, comparison or any process whatsoever... it has its own quality which consists of nothing else"» (GUPTA 2018; Пирс здесь цитируется по: РеIRсе 1960: 152).

11 «Secondness manifests itself when firstness relates to another object through either relation, compulsion, effect, dependence, independence, negation, occurrence, result or reality» (GUPTA 2018). 
рядом, то никто, решительно никто не взял бы на себя определить, который именно настоящий Голядкин, а который поддельный, кто старенький и кто новенький, кто оригинал и кто копия» (147). Правда, согласно логике сюжетосложения и противопоставления cтарого / известного vs. нового / неизвестного, Голядкин-старший имеет неоспоримую первичность бытия по отношению к Голядкину-младшему и в том смысле, что последний как «новопоступающий» понимается и как новый комплексный знак, ${ }^{12}$ созидающий референтное отношение к старому знаку (через Голядкина-младшего получает смысловое определение Голядкин-старший, «наш герой»). Однозначность в смысле указанной однонаправленности все же разрушается, когда возникает идея неизвестности в том отношении, кто оригинал (первичный знак) и кто копия (вторичный знак). Такая тематизация смены перспективы выдвигает на передний план феномен взаимности: получаем ли мы характеристику «нашего героя» через его двойника, или, наоборот, фигура двойника характеризуется через Голядкина-старшего, или, идя еще дальше, они взаимно определяют друг друга в обратно симметрической реляции знака и референта, - реляции, которая, таким образом, тоже удваивается? В относимости младшего персонажа к старшему как референту открывается возможность толкования в фигуре Голядкина-старшего того, что «само по себе» не было бы понятно; в то же время, не зная господина Голядкина «самого по себе» (сюжетная независимость его фигуры длится до начала пятой главы), трудно было бы понять, в каких отношениях определяется образ Голядкина-младшего чертами «нашего героя». Читатель, таким образом, вступает в такие семиотические условия, при которых возникает взаимное, и таким образом удвоенное и динамическое отношение старой и новой фигур как комплексных знаков. Именно такая взаимосвязь подчеркивается в тематизации, согласно которой нельзя определить, кто по отношению к кому является оригиналом, и в каком образе проявляется копия (речь, конечно, идет об определенности не в событийно-сюжетном, а более абстрактном семиотическом смысле).

Обострение дилеммы соотношения нового и старого знака, с точки зрения их взаимопроецированного референтного статуса, получает явное отражение в той части действия повести (в пятой главе), где описывается появление двойника, и где осмысляется природа признаковости таких индивидуальных черт, которые любопытным образом связывают двух персонажей в интересной композиции повторов, - как рекуррентных, так и транспозиционных.

\section{2. Транспозиция моторных деталей фигуры Голядкина-старшего}

Взаимосвязь первичности и вторичности, - подводящая (за счет удвоения) к двухсторонней проекции референтных статусов в семантическом соотношении двух персонажей, связана со своеобразной амбивалентностью, моделированной в событийном сюжете в аспекте топографического расположения двух героев, точнее, корреляции их пространственной динамики. Главными мотивами такого взаимоотношения оказываются движения двойника к Голядкину и его движения к своему двойнику. Признаки движения, как это выясняется уже из обилия моторных образов, на которое обратил внимание Виноградов,

12 Под комплексным знаком понимается соединение означающего и означаемого в соссюровском понимании. 
теснейшим образом связаны с двойственностью самого главного героя произведения Достоевского.

В начале пятой главы выделяется идея, заложенная в последнем сообщении предыдущей главы в следующем виде: «наш герой» «сорвался с места, на котором доселе стоял, как прикованный, и стремглав бросился вон, куда-нибудь, на воздух, на волю, куда глаза глядят...» $\left(137^{13}\right)$. Жест Голядкина стремглав броситься вон продолжается в тематическом мотиве бегство, имеющем последовательное развитие. Сначала утверждается, что «Голядкин, вне себя, выбежал на набережную Фонтанки», затем повествователь подробно останавливается на теме способности героя бежать: «Господин Голядкин был убит, - убит вполне, в полном смысле слова, и если сохранил в настоящую минуту способность бежать, то единственно по какому-то чуду, по чуду, которому он сам, наконец, верить отказывался» (138). Мотивы убит и бежать наглядно повторяют двойственность моторных реакций Голядкина (их отсутствие и наличие) из конца предыдущей главы, где изображается, как его выгоняют из дома Берендеева - сначала он, как «прикованный», стоит на своем месте, откуда наконец-то «сорвался», «стремглав» выбегая окончательно из пространства, в котором его осрамили. В продолжении этого эпизода ноябрьская петербургская погода «атакует» «убитого несчастиями» Голядкина (138). Прикованность с признаком неподвижности, а затем бег стремглав интегрируются (получая подробную тематизацию) в мотив бежать при убитости, а в образе врага, убивающего «нашего героя», тоже сочетаются предыдущие «враги», которые выгнали его из пространства Берендеевых, и «атакующая» его погода. Наблюдается повтор с результатом смыслового сгущения (интеграция превращает два противоположных мотива в один ансамбль - в бегстве проявляется также убитость), и параллельно с этим ресемантизируется смысл убить в форме атаковать, сопровождаясь транспонированием субъекта врага в субъекта погоды. Процесс аналогичен тому, как это происходит в случае соединения движения и остановки путем гармоничного интегрирования обоих смыслов в единый образ: «непогода» набрасывается на героя «как бы нарочно сообщась и согласясь со всеми врагами его отработать» (138). Все враги в данном месте текста осмысляются многочисленными деталями, соположенными в качестве сил, от которых следует бежать, «спасаясь от врагов, от преследований, от града щелчков, на него занесенных, от крика встревоженных старух, от оханья и аханья женщин и от убийственных взглядов Андрея Филипповича» (138). Подобным образом перечисляются все признаки непогоды ноябрьской ночи как врага («Ночь была ужасная, ноябрьская, - мокрая, туманная, дождливая, снежливая, чреватая флюсами, насморками, лихорадками, жабами, горячками всех возможных родов и сортов - одним словом, всеми дарами петербургского ноября», 138). В духе подобной синтаксической композиции определения смысла (в форме подробного списка элементов, а затем приведения их в общий образ), при единицах «всеми врагами» (от которых нужно бежать) и «всеми дарами петербургского ноября», слагающихся из всех возможных родов и сортов, еще сильнее подчеркивается поэтический прием интеграции семантических составляющих. В ее основе лежит первичный процесс детализации путем нагромождающихся повторов, компоненты которых в итоге включаются в целостное единство.

13 Мотив «стремглав броситься вон» (137, см. затем трансформацию: «бежал без оглядки», 139) также причисляется к компонентам интертекста, формирующегося в художественном диалоге с «Медным всадником» Пушкина (Викторович 2019). 
Наблюдается тот принцип исчерпывающего деления мира, о котором выше, выясняя в повести Достоевского величайшую степень сегментации благодаря «регистрации всех возможных действий» (Виноградов), говорилось, что он ведет к порождению смысла в эквивалентизирующих процессах, в рамках рекуррентных повторов. Они выдвигают на передний план феномен беспризнаковости. В приведенном примере из начала пятой главы, тем не менее, содержится такой тип нагромождения деталей (семантических признаков всех врагов, заставляющих Голядкина бежать, включая атакующую погоду), при котором происходят наглядные трансформации с результатом смысловой транспозиции. Они касаются отождествления вредящих Голядкину субъектов, их характеристики, а также воплощения смыслового объема всего этого в едином образе. К осуществлению такой транспозиции принадлежит следующее: сначала повторяется и видоизменяется мотив, а трансформация и транспозиция смысла завершается сгущением, интеграцией двух компонентов в один образ, см. прикованность $\rightarrow$ убитость [статичность]; убить атаковать; враги $\rightarrow$ непогода; в этом процессе возникает значение интеграции как инклюзивность: убитость в бегстве; (не)погода и «все враги» вместе / в «согласии» (см. еще раз отражение на уровне действия: «согласясь со всеми врагами его»). Такая динамика с транспозициями, в противоположность рекуррентной динамике под знаком статичности, наглядно и ощутимо ведет вперед процессы смыслопорождения. В этом духе фигура Голядкина наделяется новым признаком, когда описывается, как на него «и без того, убитого несчастиямu», нападает «снег, дождь и всё то, чему даже имени не бывает, когда разыграется вьюга и хмара под петербургским ноябрьским небом» (138). В единый образ, возникающий за счет транспозиций всех врагов - всех невзгод погоды, таким образом, входит и мотив несчастий, который затем перевоплощается в гонение судьбы (138). Формированием окончательного этапа данной линии семантизации компоненты единого образа враждебной Голядкину cyдьбы соединяются в его собственной фигуре: «господин Голядкин глядит теперь так, как будто сам от себя куда-то спрятаться хочет... желал теперь убежать от себя самого, но даже совсем уничтожиться, не быть, в прах обратиться» (139).

В русле процитированной идеи проявляется новая транспозиция, которая, в то же время, своеобразным образом возвращает чтение к двум полюсам телесной моторной экспрессии, заложенной в противопоставлении остановки (прикованность, убитость) и бега героя. Он сам хочет уничтожиться, превратить свое бытие в состояние не быть,

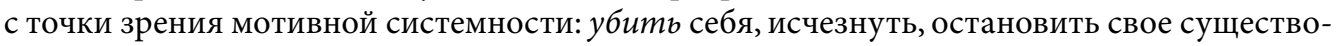
вание до крайнего пункта. Этому и соответствует его действительная физическая остановка: «Он... останавливался неподвижно, как столб, посреди тротуара; в это мгновение он умирал, исчезал» (139). Повторяется затем и другой полюс движения, подобно тому, как это происходит в конце четвертой главы, и как это продолжается в начале пятой: «потом вдруг срывался как бешеный с места и бежал, бежал без оглядки, как будто спасаясь от чьей-то погони, от какого-то еще более ужасного бедствия...» (139). Цикличность повтора двух моторных полюсов как бы дает ощущение рекуррентности: «Наконец, в истощении сил, господин Голядкин остановился, оперся на перила набережной в положении человека, у которого вдруг, совсем неожиданно, потекла носом кровь, и пристально стал смотреть на мутную, черную воду Фонтанки» (139).

Подводя итоги представленным до сих пор примерам внутренней конфликтности моторных образов Голядкина (в корреляции стремительного движения и полной остановки), можно прийти к выводу, что повторы систематично обладают семантической двули- 
костью в том смысле, что они сочетают рекуррентную и транспозиционную динамику. Рекуррентность обеспечивает связность текста, включая в него повторы эквивалентов, внушающих устойчивость признаков, при которых нагромождаются лишь многочисленные варианты инвариантных мотивов и усиливается логика их сочетания (вроде, например, соотношения конца четвертой и начала пятой глав; или вроде повторов разнонаправленных моторных жестов в процессе бегства). В то же время, указанное выше семантическое сгущение / интеграция воплощает, например, такую линию трансформаций, которая транспонирует субъекта врага, отодвигая его от понятий «всех врагов» человеческого происхождения и невзгод погоды через несчастия судьбы, и в итоге проецируя этого субъекта на образ самого Голядкина. Он в этом процессе транспозиций незаметно наделяется новым атрибутом: убитый врагами, будучи самому себе собственным врагом, Голядкин скорее хочет уничтожиться, чем быть догнанным самим собой. В этом духе происходит трансформация: «убитый» чужими людьми (чужой индивиду судьбой) $\rightarrow$ хочет по собственной воле «не быть», чтобы избегнуть встречи с самим собой. Подобным образом наносится на образ героя признак несчастий судьбы в качестве его собственного несчастия. Этой последней смысловой трансфигурации субъектности «врагов» Голядкина соответствуют все подробности тоски героя - «пискливый, дребезжащий концерт» погоды, «уныло слыш<имые> хлест и журчание воды» (138) созвучны состоянию души Голядкина. Он одинок («Итак, один только господин Голядкин, один с своим отчаянием, трусил в это время», 138), один как сирота. Его бегство называется «тоскливой побежкой» (ср. 138), по ходу которой он достигает крайнего «отчаяния», до конца сопровождаемого страхом (см. трусость) героя. ${ }^{14}$

Рекуррентность, устойчивый повтор внутренней конфликтности моторного образа, таким образом, систематически переписывается динамикой транспозиций, в результате чего перевоплощаются единицы повтора: интерпретируется герой в новом освещении, он подвержен самогонению и он страстно, все интенсивнее старается освободиться от своего нового «я», ${ }^{15}$ от аномалий которого он «дошел до такого отчаяния, так был истерзан, так был измучен, до того изнемог и опал и без того уже слабыми остатками духа, что позабыл обо всем» (139). Стремление «сам от себя куда-то прятаться», «сам от себя убежать» в целях, чтобы «не быть», достигает своей кульминационной точки в состоянии, когда из-за полного чувства отчаяния, истерзанности и измученности Голядкин падает в «полное забвение обо всем». Мотив большой вариативности и рекурсивности «совсем уничтожиться, в прах обратиться» (умереть, погибнуть), до самого конца произведения несущий значение как полного исчезновения, так и остановки, в указанном здесь месте переходит в мотив самозабвения (139). Такое перевоплощение, доводя до крайнего момента семантизацию желания Голядкина «не быть» в своей новой борме (отказ новому «я» в существовании), тем не менее, оказывается поворотным моментом в развертывании сюжета героя. Именно такой поворот обозначается образом двойника. Он воплощает осложненную структуру рекуррентности и транспозиции. Ведь благодаря двойнику удваивается Голядкин как ли-

14 О диспозиции тоски более детально см. в нашей указанной выше другой статье о «Двойнике» (Кроо 2020). Ср. Ковач 2005.

15 То есть от «я», действие которого принесло результат, что героя два раза выгоняют из дома Берендеевых. Р. Б. Андерсон различает в двух Голядкиных «две когнитивные парадигмы» (ANDERSON 1986: 14), из которых Голядкину-старшему принадлежит желание достигнуть высшего идеального места коллективности, в то время как его двойник следует ментально принципам утилитаризма. 
тературный персонаж (минимальная форма рекуррентности) таким образом, что черты «нашего героя» проецируются на «новоприбывшего», «новопоступившего» (146) персонажа (транспозиция). В то же время появление двойника означает момент внутреннего перевоплощения (трансформация) самого Голядкина-старшего (см. остановку как самозабвение).

Голядкин-младший в пятой главе появляется не без семантического опосредования. Фигура вводится в сюжет через призму сознания Голядкина-старшего, проходящего путь от незнания чужого человека к осознанию в нем самого себя. При этом в пространственной динамике «нашего героя» на смену движению двойника к Голядкину в контексте гонения врагами (бегство от) приходит движение героя к своему двойнику (к самому себе). ${ }^{16}$ Пространственный микросюжет бегство от $\rightarrow$ приближение $\kappa$ (остановка) транспонирует рекуррентную двойственность Голядкина-старшего (двойник) в такой семантический конструкт, в котором взаимоотношение двух фигур составляет осложненную интегративную конфигурацию. В ней отражается трансформация «нашего героя» в своем процессуальном развертывании. В то же время процесс интеграции смысловых единиц во все более и более крупные семантические формации вырисовывает динамику текстопорождения. С этим связано то, что фигура двойника может участвовать в самоописании текстовой эволюции повести Достоевского.

\section{ЛИТЕРАТУРА}

Викторович 2019 = Викторович В. А. «Медный всадник» в творчестве Ф. М. Достоевского. Проблемы исторической поэтики 2019/4: 107-122.

ВиногрАдов 1976 = Виноградов В. В. К морфологии натурального стиля. ОПЫт лингвистического анализа петербургской поэмы «Двойник». В кн.: ВиногрАдов В. В. Поэтика русской литературы. Избранные труды. Москва: «Наука», 1976. 101-140.

Достоввский 1972 = Достоввский Ф. М. Полное собрание сочинений в 30 томах. Т. 1. Бедные люди. Повести и рассказы 1846-1847. Ленинград: «Наука», 1972.

ЗАХАРОв 1985 = ЗАХАРов В. Н. Поэтика повести. В кн.: ЗАХАРов В. Н. Система жанров Достоевского. Типология и поэтика. Ленинград: «Издательство Ленинградского университета», 1985. 65-112.

КирАй 1969 = КирАй Д. Композиция сюЖета романа «Двойник. Приключения господина Голядкина». Acta Litteraria Academiae Scientiarum Hungaricae 11 (1969): 351-378.

Ковач 2005 = Ковач А. Angustia: Тоска У Достоевского. В Кн.: Хетени Ж., Соколова-Атанасова Д. (ред.) Russica Hungarica. Исследования по русской литературе и культуре. Русистика в Будапештском университете. Москва-Вudapest: «Водолей», 2005. 2005. 100-125.

МАКлАКОвА-ШоровА 2016 = МАКЛАКовА Н. В., ШоровА Е. В. «Повтор» и «Повторение» в литературоведении и философском дискурсе XIX-XX вв. (к вопросу разграничения понятий). Молодой ученый 132 (2016): 916-920.

16 Событийные рамки такого сдвига в направлении движения тематизируются как бегство из дома Берендеева и вбежание в собственный (голядкинский) дом. Это соответствует семантическому сюжету, несущему трансформацию чужое $\rightarrow$ свое. О значении данных имен в (культурно)-историческом контексте см. Топоров 1982. Об историческом подтексте детально см. ЗАХАРов 1985: 89-95. 
ПиРс $2001=$ ПиРс Ч. С. Принцииы философии. Т. 1. Санкт-Петербург: «Санкт-Петербургское философское общество», 2001.

Сироткин 2017 = Сироткин Н. С. Русский и немецкий авангард с точки зрения семиотики Ч. С. Пирса. Материаль к теории метасемиотических систем. Москва: «Издательские решения», 2017.

Смирнов 2001 = Смирнов И. Смысл как таковой. Санкт-Петербург: «Академический проект», 2001.

Топоров 1982 = Топоров В. Н. Еще раз об «умышленности» Достоевского. В кн.: Исаков С. Г. (ред.) Finitis duodecim lustris. Сборник статей к 60-летию проф. Ю. М. Лотмана. Таллин: «Ээсти раамат», 1982. 126-132.

ФАустов $2019=$ ФАустов А. А. О повествовательной дисперсии: роман Ф. М. Достоевского «Идиот». Культура и текст 2019/4: 6-21.

Цивьян 1976 = Цивьян Т. В. О структуре времени и пространства в романе Достоевского «Подросток». Russian Literature 4 (1976): 203-255.

Шкловский 1957 = Шкловский В. За и против. Заметки о Достоевском. Москва: «Советский писатель», 1957.

Шмид 2003 = Шмид В. Нарратология. Москва: «Языки славянской культуры», 2003.

Anderson 1986 = Anderson R. B. The Double: Duality and Conflict. In: Anderson R. B. Dostoevsky: Myths of Duality. (Humanities Monograph Series 58.) Gainesville: University of Florida Press, 1986. 12-26.

GaSPERETTI 1989 = GasPeretTI D. The Double: Dostoevskij’s Self-Effacing Narrative. Slavic and East European Journal 33 (1989): 217-234.

GuPTA 2018 = GuPTA T. Understanding Semiotics: Firstness, Secondness and Thirdness. https://www.linkedin.com/pulse/understanding-semiotics-firstness-secondness-thirdness-tanvi-gupta.

KROо 1998 = KROо K. Szövegiség és metaszövegiség Dosztojevszkij $A$ hasonmás címü müvében [Текстовость и метатекстовость в «Двойнике» Достоевского]. In: Zoltán András (szerk.): Nyelv, stílus, irodalom. Köszöntö könyv Péter Mihály 70. születésnapjára. Budapest: ELTE, 1998. 331-337.

KroO-TOROP 2018 = KROO K., TOROP P. Text dynamics: Renewing challenges for semiotics of literature. Sign Systems Studies 46 (2018): 143-167.

LACHMANN 1997 = LACHMANn R. The Doppelgänger as a Simulacrum: Gogol, Dostoevsky, and Nabokov. In: LaChMANN R. Memory and Literature. Intertextuality in Russian Modernism. Minneapolis: University of Minnesota Press, 1997. 298-314.

Peirce $1960=$ Peirce C. S. The Collected Papers of Charles Sanders Peirce. Edited by Charles Hartshorne and Paul Weiss. Vol. 1. The Principles of Philosophy. Harvard University Press, 1960.

Rosenshield 1996 = Rosenshield G. The Bronze Horseman and The Double: The Depoeticization of the Myth of Petersburg in the Young Dostoevskii. Slavic Review 55 (1996): 399-428.

Trubetzkoy $1948=$ Trubetzkoy N. S. The Style of Poor Folk and The Double. The American Slavic and East European Review 7 (1948): 150-170. 


\section{KATALIN KROÓ \\ Department of Russian Language and Literature, Eötvös Loránd University (Budapest) Tomsk Polytechnic University \\ Types of Textual Dynamics in the Light of the Phenomenon of Semantic Attributes in Fyodor Dostoevsky's Novella The Double (Part 1)}

The paper examines the poetic principles and functions of two sorts of structural-semantic logic influencing the emergence of textual dynamics in The Double. Paradoxically, the main developmental line consists in a highly repetitive structure of permanent reiteration of fixed narrative units, motifs, and lexical items in the text. Their constant recurrence (cf. events, character traits, semantic attributes, and elements of stable idiomatic phrases) creates the impression of a static world model in which no changes occur. This may be called recursive dynamics under the sign of a static state. Transpositional dynamics, on the other hand, can be regarded as the second direction of the textual developmental movement, producing the mechanism for meaning-generation. Transposition is interpreted broadly, in the paper, with a special accent on 1) meaning transfigurations and projections through the shift from the uniformity of semantic attributes to the acquiring of new attributes by the signifier or the signified (the problem of reference); 2) processes of semantic integration concerning the inclusion of smaller semantic units into larger ones (semantic attribute $\rightarrow$ motif $\rightarrow$ character figure).

The purpose of the paper is to clarify the reciprocity (the special interaction) of the two types of dynamics. The semantic formation under scrutiny embodied by the smallest unit of Golyadkin's motoric-verbal expression has a double orientation based on the correlation of motion and stop interpreted by V. Vinogradov in his famous study. From the perspective of the paper's research object, this narrative and linguistic unit is examined as a recursive motif pair with a special capacity of transformation through transposition. It is demonstrated in detail, within the close reading of the fifth chapter, where Golyadkin's double appears, how transposition works through a process of semantic integrations. The meaning of enemy is shifted from human rivals to Petersburg weather and human fate as new subjects, associated with mythology and literary culture (intertexts), leading up to the interpretation of Golyadkin's personality. The protagonist's figure is projected upon his double through many semantic attributes. The "melancholy flight" as his encounter with himself presents him as an awakening hero, who as a character is developed gradually, including his double as his figure-transposition which also embodies a dynamic semantic pattern. The correlation of Golyadkin and his double in the context of firstness and secondness is also put into the context of Peircean semiotics.

Keywords: Dostoevsky, The Double, text-dynamics, recursivity, transpositional dynamics, transformation, integration, semantic attributes, motoric-verbal expression, semiotics

Open Access. This is an open-access article distributed under the terms of the Creative Commons Attribution 4.0 International License (https://creativecommons.org/licenses/by/4.0), which permits unrestricted use, distribution, and reproduction in any medium, provided the original author and source are credited, a link to the CC License is provided, and changes - if any - are indicated. (SID_1) 